\title{
Thoughts on Teacher Management Abilities from the Perspective of Enterprise-Style Classroom Management
}

\author{
Yin Wentao \\ School Of Marxism of Xi'an Fanyi University \\ Shaanxi province, China
}

\begin{abstract}
In the enterprise-style classroom management mode, both teachers and students participate in classroom management, which helps to establish harmonious relationships between teachers and students. Through students' selfmanagement, students' subjectivity is emphasized and students' sense of ownership is stimulated. This mode puts forward higher requirements for teachers' management and practical abilities. To improve teachers' management and practical abilities, it is necessary to change teachers' ideological concepts, improve the training mechanisms for teaching abilities, build ability-based training platforms, provide supporting mechanisms, and encourage enterprises to participate in education activities. This research provides references for education reform development and teaching management improvement in China.
\end{abstract}

Keywords-Enterprise-style classroom management; Management ability; Ability improvement

\section{INTRODUCTION}

Effective classroom management guarantees smooth teaching. Similar to all organizational management, classroom management aims at pursuing high efficiency [1]. Effective classroom management strategies are important for ensuring the effectiveness of classroom teaching. Problems in classroom management can be effectively solved only if effective classroom management strategies are adopted to regulate classroom behavior. Enterprise-style management plays an important role in meeting social needs, easing economic pressure, and enhancing social influence. Therefore, many industries are actively exploring enterprise-style models from their own interests [2-4]. Colleges and universities actively attempt enterprise-style management. They use the advanced concepts and experience of enterprise style management to explore enterprise- style management in terms of basic management. For example, enterprise- style enterprise- style can enhance financial management efficiency of colleges and universities [5]. Therefore, enterprise-style management is a new attempt to improve the management mode of colleges and universities. Introducing enterprise-style modes to classroom management of higher vocational education provides new ideas for the innovation of classroom management. The contents of enterprise-style classroom management are as follows:
- Introduce enterprise systems into classroom management. Teachers and students jointly develop an enterprise-style classroom management system, and establish enterprise-style classroom attendance, reward, and punishment, and assessment systems.

- Transform teachers' roles in classroom management. Teachers are not only the theoretical instructors of knowledge but also the workshop managers who apply the enterprise-style classroom management system to classroom management.

- Transform students' roles into employee roles. Through obeying various rules in enterprise-style classroom management, students can realize self-management in the class. At the same time, some students become classroom management assistants of teachers. Common members change their roles into employees. In this way, students have triple identities.

- Teachers and students have both teacher-student relationship and management relationship between enterprise managers and employees. Such enterprisestyle classroom management can enhance students' selfmanagement abilities, stimulate students' curiosity, and help form a harmonious teacher-student relationship. In early practice, enterprise-style classroom management mode fully realizes student self-management and cultivates students' sense of innovation.

II. ENTERPRISE-STYLE ClaSSROOM MANAGEMENT PUTS FORWARD HIGHER REQUIREMENTS ON TEACHERS' ABILITIES

Cultivating practical and applied talents has increasingly become an educational characteristic of colleges and universities, which are requirements for new industrialization, informationization, and urbanization with Chinese characteristics in the new era. The enterprise-style classroom management mode effectively realizes the combination of theory and practice, and better cultivates high-quality applied talents to meet our society needs. Enterprise-style classroom management has changed from traditional management to modern management. In this mode, teachers have been transformed from control to service. It puts forward higher 
requirements for teachers' management abilities, practical abilities, and comprehensive quality.

\section{A. Teachers require strong practical abilities.}

Teachers must have strong theoretical and practical abilities and certain vocational and operational skills. They scan properly control and demonstration roles in classroom management and provide teaching guidance for students' selfmanagement and development.

\section{B. Teachers must have certain organizational management abilities.}

Teacher's organizational management abilities, that is, resource integration and allocation abilities as well as leadership, fundamentally improve organizational efficiency. To have organizational management abilities, teachers must have certain management resources [6].

In the enterprise-style classroom management mode, teachers are not only theoretical instructors of knowledge but also workshop managers. To apply the enterprise-style classroom management system to the classroom management, teachers must have certain management abilities, realizing orderly classroom management. In the classroom management, teachers should organize a management team as management experts who serve as a communication bridge between teachers and students. According to teaching objectives, students should actively participate in various types of social practice activities, have certain decision-making abilities, and can scientifically analyze and solve problems in classroom management to find the optimal solution. In addition, they must have certain decision-making and execution abilities to help students better understand the development needs of corporate culture and market economy.

\section{Teachers must have classroom coordination and management abilities.}

In the enterprise-style classroom management mode, teachers and students have both teacher-student relationship and management relationship between enterprise managers and employees. The ultimate goal is to achieve orderly management and coordinated development. First, coordinate the relationship between teachers and students. Teachers guide students in self-management. Second, coordinate the relationship between students. Through enterprise-style management, create a good learning atmosphere and ultimately achieve students' harmonious coexistence. Third, coordinate the relationship between students and social practice (corporate management). Through enterprise-style classroom management, introduce the enterprise management system into classroom management, instructing students to participate in management, understanding the enterprise-style management system, cultivating students' hands-on practical abilities, stimulating students' creativity, and cultivating students' abilities to serve the society.

\section{Teachers should understand the law of development for enterprises}

The enterprise-style classroom management mode introduces the enterprise-style system into the classroom management, cultivates students' awareness of obeying rules, and requires teachers to better understand the management rules of enterprises. Through enterprise-style classroom management, the management law of the enterprise is infiltrated into the class management, instructing students to understand the basic requirements of enterprise management. However, teachers need to understand the development needs of the industry and have certain communication skills.

\section{PROBLEMS IN THE IMPROVEMENT OF TEACHERS' MANAGEMENT ABILITIES FROM THE PERSPECTIVE OF ENTERPRISE-STYLE CLASSROOM MANAGEMENT}

In addition to the influence of objective environments, classroom management effects are also restricted by main factors, especially teachers' own quality and management abilities. Teachers still have certain deficiencies in their professional literacy, ability improvement mechanisms, and improvement platforms, which affect classroom management effectiveness.

\section{A. Teachers' own conditions restrict management ability construction.}

Clear job responsibilities, familiar working environments, and understanding of students' conditions are necessary for teachers to carry out student classroom management. To achieve effective classroom management, teachers need to understand students' needs, establish good relationships with students, and stimulate students' self-management awareness. In addition, they also need to have abilities to prevent and deal with emergent classroom problems. However, teachers have insufficient management abilities in classroom management practice. For example, they have bias in the understanding of student classroom management, and therefore blindly carry out student management work. In the classroom management, teachers have heavy teaching tasks and big research pressures, leading to teacher-based teaching mode. Teachers lack effective communication with students, and adopt criticism and preaching mode in classroom management. Lacking sense of innovation, teachers in the classroom management adhere to the rules, follow the old, and ignore the cultivation of students' abilities, especially practical and hands-on abilities. In addition, they are not good at creating good classroom atmospheres and have weak abilities in preventing and dealing with classroom problems.

\section{B. Relevant mechanisms are unsound and teachers therefore lack the motivation to make improvements.}

In the process of education and teaching reform, management of the internal education system is complicated. The change of organizational organizations and the choice of teaching systems will have impacts on the ways that teachers manage and guide students, even leading to a transformative change [7]. Some colleges and universities still value theory more than practice, which incorrectly leads student 
management. As a result, it is difficult for classroom management to achieve desired effects. Scientific classroom management not only conforms to the education development trend but also requires institutional guarantees that match classroom management much more.

The incentive, benefit guiding, information feedback, and risk management mechanisms required for enterprise-style classroom management have not been effectively established yet. Without guarantee of related mechanisms, teachers' enthusiasm in improving their practical abilities are eliminated. Colleges and universities neglect the construction of teachers' and students' management abilities, especially lacking on-thejob training for teachers. Even if teachers accumulate rich experience of student management in practice, they still do not have relevant theoretical support.

\section{The construction of higher vocational teachers' ability improvement platforms are lagged behind.}

It is a realistic and feasible to use modern technical means and ability improvement platforms to improve practical abilities of higher vocational teachers. However, the reality is that platform construction has not attracted the full attention of teachers and management departments. The construction of communication, cooperation, and ability improvement platforms is not going well, which restricts the improvement of teachers' practical and management abilities.

\section{Enterprise-style classroom management is also affected by insufficient enterprise participation.}

The cultivation of teachers' management and practical abilities depends on human resources and environments. The low participate of enterprises makes school-enterprise cooperation difficult, obsessing the development of education, especially vocational education. Enterprises may worry that internships disrupt their production order or they do not want to provide such resources, which lowers teachers' enthusiasm for management learning.

\section{STRATEgIES FOR IMPROVING TEACHERS' MANAGEMENT ABILITIES}

The ultimate objective of enterprise-style classroom management is to maximize the development of each student. Teachers' guidance and management are necessary for students' comprehensive development. Teachers should come out of traditional roles, clarify their roles in enterprise-style classroom management, and enhance their comprehensive abilities [8].

\section{A. Establish scientific classroom management concepts.}

Enterprise-style classroom management aims at realizing students' self-management and promoting their comprehensive and harmonious development. Teachers need to deeply research into classroom management concepts, cultivate student-oriented awareness, motivate students to participate in classroom management, and improve classroom management skills. According to the different characteristics of students, teachers can give students management responsibility so that students become small classroom management assistants. In this way, students can establish harmonious interpersonal relationships in classroom management. In addition, teachers need to improve the abilities of preventing and processing classroom problems, formulate reasonable classroom rules, and improve the abilities to make preparations before the class.

\section{B. Perfect practical ability training mechanisms for teachers} and improve teachers' classroom management abilities.

Establish teacher training ability training mechanisms to enhance teachers' management abilities. The improvement of teachers' management abilities depends on certain external conditions, which can be provided through management systems of schools, cultural atmosphere construction, and team building. In this way, teacher training can be normalized. Considering school development conditions, we need to establish and improve relevant systems for developing teacher management capabilities and formulate training plans. We also need to establish mentor systems for young teachers, arranging teachers with rich teaching and management experience as the mentors of new teachers. In this way, experienced teachers can provide guidance for new teachers in classroom management. In addition, we can make innovation on our classroom management evaluation system. Past classroom evaluation focuses on results instead of processes. Now, we need to use a comprehensive evaluation system which is centered on innovative spirit and practical operational capabilities. Establish corresponding assessment and reward mechanism, and comprehensively assess teachers in terms of practical teaching and classroom management so as to scientifically evaluate teachers' work.

\section{Strengthen the construction of training platform and improve teachers' classroom management abilities.}

Teachers' practical abilities in enterprise-style classroom management have increasingly become an important part of teaching management. The practical ability training platform can be used to complete the practice training outside schools, helping better understand enterprise management mode and social development needs. Through further promotion of corporate cooperation models, a group of experts with practical abilities will be introduced to bring corporate awareness into classrooms, and encourage teachers to work part-time in enterprises, helping improve teachers' practical abilities.

\section{Establish guarantee mechanisms compatible with enterprise-style management.}

Enterprise-style classroom management mode requires students to achieve self-management. This mode greatly expands teaching management space and time but has certain risks. Therefore, a complete guarantee mechanism needs to be established for enterprise-style management. For example, establish a reporting system so that related operations can be well documented. In classroom management, the rights and responsibilities of teachers are reasonably divided. Formulate a series of systems to strongly guarantee teachers' ability improvement. 


\section{E. Encourage enterprises to participate and enhance the awareness of corporate management for teachers.}

Our government needs to improve relevant systems and encourage enterprises to set up practical positions for teachers. Expenses incurred for practical positions should be reduced according to tax policies. In addition, the government needs to encourage enterprises to participate in the construction of training bases for teacher management ability training, and encourage enterprises to assign relevant experts for the training.

\section{CONCLUSION}

As a new attempt to the management of colleges and universities, enterprise-style management improve student's self-management. Difficulties in classroom management can be solved only if higher vocational teachers contentiously improve their management abilities and comprehensive practice abilities and clarify their roles in enterprise-style classroom management.

\section{ACKNOWLEDGMENT}

Fund project: This paper is the research result of Research on the Construction of Enterprise-Style Classroom Management in Higher Vocational Colleges of National Science Education Project in Twelfth-Five Planning in 2015. (Project No.: EJA150377, Director: Guo Huining
Yin Wentao, male, born in 1984, working as an lecturer in School Of Marxism of Xi'an Fanyi University in Shaanxi province and majoring in ideological and political education

\section{REFERENCES}

[1] Zhai Xianjun. Classroom Teaching Abilities Are Primary Professional Abilities of College Teachers [J]. Chinese University Teaching, 2016 (03): 71-75.

[2] Tian Rong, Lucy. Jordan. Socialized and Enterprise-Style Non-profit Organizations: Models and Strategies [J]. Journal of East China University of Science and Technology (Social Science Edition), 2016(04): 104-112.

[3] Sun Xinhua. Enterprise Operation of Benefiting-Farmers Projects: Mechanisms, Problems and Countermeasures [J]. Journal of Anhui Normal University (Humanities and Social Sciences Edition), 2014 (01): 98-104.

[4] Liu Hui, Tian Hua, Zhao Wenyi. Enterprise, Marketization, Industrialization - Logical Construction of Academic Journal Publishing Development [J].Science \& Technology and Publishing, 2014(01):37-39.

[5] Liu Hongmei. Exploring the Enterprise Management Mode of Financial Management in Higher Vocational Colleges [J]. Finance and Accounting News, 2012(05): 94-95.

[6] Zhuang Xizhen. Model of Vocational College Teachers' Ability Structure in Typology [J]. China Higher Education Research, 2015(11): 101-105.

[7] Shi Lulu, Wang Dongmei. Research on Teacher's Student Management Ability Construction [J]. Teaching and Management, 2016(10): 76-78.

[8] He Juling. Ontological Pursuit of Teacher Identities [J].Journal of Shaanxi Normal University: Philosophy and Social Sciences. 2013(2). 